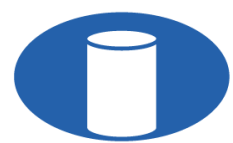

IBRACON

ORIGINAL ARTICLE

\title{
Influence of the supplementary reinforcement on the shear strength of beams with prefabricated truss stirrups
}

\section{Influência da armadura suplementar na resistência ao cisalhamento de vigas com estribos treliçados pré-fabricados}

\author{
Rosângela Silva Pinto ${ }^{\mathrm{a}}$ \\ Vanessa Carolaine Sousa ${ }^{a}$ (D) \\ Luamim Sales Tapajós ${ }^{\mathrm{b}}$ (D) \\ Maurício de Pina Ferreira ${ }^{c}$ (D) \\ Aarão Ferreira Lima Neto ${ }^{\mathrm{a}}$
}

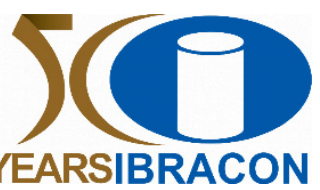

\footnotetext{
${ }^{a}$ Universidade Federal do Pará - UFPA, Nucleus of Amazonian Development in Engineering, Postgraduate Program in Infrastructure Engineering and Energy Development, Tucuruí, PA, Brasil

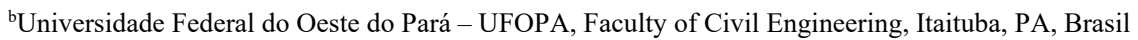

'Universidade Federal do Pará - UFPA, Institute of Technology, Faculty of Civil Engineering, Belém, PA, Brasil
}

Received 22 October 2020

Accepted 05 May 2021

\begin{abstract}
This paper presents the results of seven experimental tests in reinforced concrete wide beams, aiming to investigate their performance when subjected to shear, using prefabricated truss stirrups as shear reinforcement, as well as a supplementary reinforcement to control cracks by delamination. The main analysed variables were: position of the supplementary reinforcement, inclination of the shear reinforcement, and spacing between stirrups. Results showed that strength increments of up to $142 \%$ were obtained using the prefabricated truss stirrups. Furthermore, the experimental results were compared with the theoretical shear strength estimates of the tested beams, following the recommendations of NBR 6118 (2014), Eurocode 2 (2004), and ACI 318 (2014), in order to evaluate the safety level of these codes when designing concrete elements subjected to shear with the reinforcement used in this paper.
\end{abstract}

Keywords: shear, shear reinforcement, supplementary reinforcement.

\begin{abstract}
Resumo: Este trabalho apresenta os resultados dos ensaios em sete vigas faixa de concreto armado, cujo objetivo foi o de investigar o desempenho dessas peças ao cisalhamento, adotando-se os estribos treliçados pré-fabricados como armadura transversal, acrescidos de uma armadura suplementar, para evitar a propagação de fissuras por delaminação. As principais variáveis analisadas foram: posição da armadura suplementar, inclinação da armadura transversal e espaçamento entre camadas de estribos. Comparando os resultados das vigas armadas ao cisalhamento com a viga de referência, verificou-se que a armadura transversal utilizada neste trabalho levou a um acréscimo de até $142 \%$ na resistência última das vigas. Além disso, foram comparados os resultados experimentais com as estimativas teóricas de resistência ao cisalhamento das vigas ensaiadas, seguindo as recomendações da NBR 6118 (2014), Eurocode 2 (2004) e ACI 318 (2014), a fim de se avaliar o nível de segurança dessas recomendações para o dimensionamento de elementos de concreto ao cisalhamento com a armadura adotada neste artigo.
\end{abstract}

Palavras-chave: cisalhamento, armadura transversal, armadura suplementar.

How to cite: R. S. Pinto; V.C. Sousa; L.S. Tapajós; M.P. Ferreira; A.F. Lima Neto "Influence of the Supplementary Reinforcement on the Shear Strength of Beams with Prefabricated Truss Stirrups," Rev. IBRACON Estrut. Mater., vol. 15, no. 1, e15106, 2022, https://doi.org/10.1590/S198341952022000100006 


\section{INTRODUCTION}

Reinforced concrete elements subjected to shear are likely to fail in a brittle way, and several authors [1-9] suggest that using shear reinforcement is the best way to improve both the shear strength and deformation capacity of reinforced concrete structural members.

However, in some cases (Figure 1), there may be difficulty in reinforcing the concrete element due to the conflict between flexural and shear reinforcement, which is the need to involve the longitudinal bars, in the case of closed stirrups (Figure 1b and Figure 1c) or the positioning of the flexural reinforcement, in the case of studs (Figure 1e).

Thus, one of the solutions to avoid clashes when positioning the transverse and longitudinal reinforcement is the use of shear reinforcement with internal anchorage, positioned between the top and bottom flexural reinforcement (Figure 1f). In addition, shear reinforcement with internal anchorage can be prefabricated, as they do not depend on the flexural reinforcement position, making the construction process faster. This greater agility in the construction process can reduce the work costs, as commented by some authors [10-12].

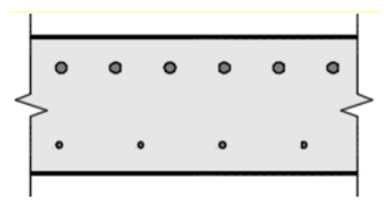

a. Flexural reinforcement

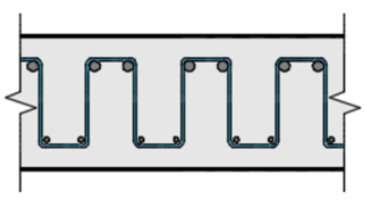

d. Continuous stirrup

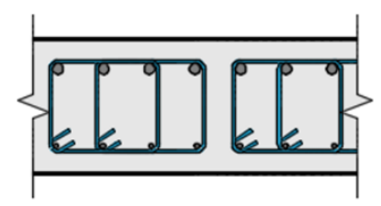

b. Closed stirrups I

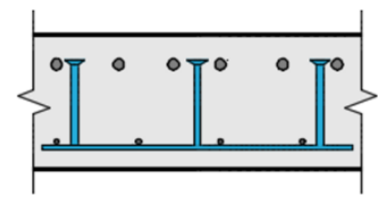

e. Studs

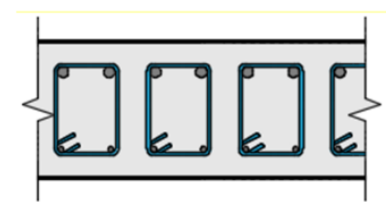

c. Closed stirrups II

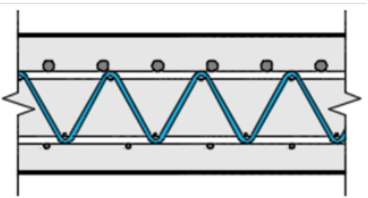

f. W stirrup

Figure 1. Shear reinforcement detailing in one-way shear (Tapajós [13])

Nevertheless, a significant reduction of the structural performance of the transverse reinforcement has been described when they are not anchored within the flexural reinforcement (see [14] and [15]). Some authors [16-18] observed that using shear reinforcement with internal anchorage in flat slabs subjected to two-way shear led to premature failures associated with the delamination effect.

Even so, it is possible to mention studies where the use of shear reinforcement with internal anchorage had satisfactory performance, and the development of cracks by delamination was not observed in some papers [19-21]. It is also worth mentioning the study of Ferreira et al. [22], who tested prefabricated truss stirrups with internal anchorage in reinforced concrete wide beams, observing the delamination in some specimens. However, Tapajós [13] tested the shear reinforcement developed by Ferreira et al. [22] with and without the addition of a u-hook as supplementary reinforcement to avoid delamination, noting that it would be possible to obtain a performance similar to that of beams with closed stirrups anchored to flexural reinforcement and studs.

Thus, this study aimed to investigate the influence of supplementary reinforcement on the shear performance of reinforced concrete elements with the prefabricated truss stirrups, as well as the angle of inclination and spacing of shear reinforcement. Seven wide beams were tested, varying the angle of inclination of the shear reinforcement and the supplementary u-hooks' position. In addition, the experimental results were compared with theoretical ones according to the recommendations of codes NBR 6118 [23], Eurocode 2 [24], and ACI 318 [25].

\section{DESIGN RECOMMENDATIONS}

The recommendations presented in [23-25] were used to estimate the tested specimens' shear resistance. It is relevant to highlight that the safety factors implicit and explicitly presented in the design equations were removed in this section to compare theoretical and experimental strengths properly. 


\subsection{NBR 6118 (2014)}

The Brazilian code presents two design models to estimate the shear strength of reinforced concrete elements. Model I considers that the shear strength of transversely reinforced beams $\left(V_{R, c s I}\right)$ is given by the sum of the contributions given by concrete $\left(V_{R, c I}\right)$ and steel $\left(V_{R, S I}\right)$, as shown in Equation 1, as well as this model assumes an inclination of the strut equal to $45^{\circ}$. The concrete contribution is calculated with Equation 2, which estimates the shear strength of a beam without transverse reinforcement and considers only the concrete's tensile strength. The contribution given by the shear reinforcement is calculated using Equation 3, and the maximum shear strength $\left(V_{R, \max I}\right)$ of a beam is limited by Equation 4 , which estimates the failure of the compressed strut.

$$
V_{R, c s I}=V_{R, c I}+V_{R, s I}
$$

$V_{R, c I}=0.6 f w_{c t k, i n f}$

$V_{R, s I}=\left(\frac{A_{s w}}{s}\right) 0.9 d f_{y w}(\operatorname{sen} \alpha+\cos \alpha)$

$$
V_{R, \max I}=0.27\left(1-\frac{f_{\mathcal{C}}}{250}\right) f_{c} b_{w} d(\cot \alpha+1)
$$

Where: $f_{c t k \text {,inf }}=0.7 f_{c t, m}$, is the fragile tensile strength of concrete in $5 \%$ of cases;

$f_{c t, m}$ is the average tensile strength of concrete, for concretes with a maximum strength of $50 \mathrm{MPa}$, calculated with $f_{c t, m}=0.3 f_{\mathrm{c}}^{2 / 3}$; $f_{c}$ is the compressive strength of concrete;

$b_{w}$ is the width of the beam section;

$d$ is the effective depth of the beam section;

$A_{s w}$ is the area of reinforcement of one layer of transverse reinforcement; $s$ is the spacing between the transverse reinforcement layers;

$f_{y w}$ is the yield strength of the transverse reinforcement, limited to $500 \mathrm{MPa}$; $\alpha$ is the angle of inclination of the transverse reinforcement in relation to the longitudinal axis.

Model II of NBR 6118 [23] considers, as well as Model I, that the shear strength of transversely reinforced beams $\left(V_{R, c s I}\right)$ is given by the contribution of concrete $\left(V_{R, c I I}\right)$ and shear reinforcement $\left(V_{R, S I I}\right)$, according to Equation 5 . In addition, Model II also considers the effects of diagonal cracking, which reduces the strut's inclination and, consequently, concrete contribution. In this model, the Brazilian code allows the variation of the strut's angle between $30^{\circ}$ and $45^{\circ}$, and concrete contribution shall be calculated with Equation 6. In this case, concrete's contribution is a function of the applied shear force $(V)$, calculated through an iterative process. The contribution of transverse reinforcement is calculated with Equation 7 and the maximum shear strength $\left(V_{R, \max } I\right)$ with Equation 8.

$V_{R c s, I I}=V_{R, c I I}+V_{R, s I I}$

$V_{R, c I I}=V_{R, c I} \frac{V_{R, \max I I}-V}{V_{R, \max I I}-V_{R, c I}} \leq V_{R, c I}$

$V_{R, s I I}=\frac{A_{S w}}{s} 0.9 d f_{y w}(\operatorname{cotg} \theta+\operatorname{cotg} \alpha) \operatorname{sen} \alpha$

$V_{R, \max I I}=0.54\left(1-\frac{f_{\mathcal{C}}}{250}\right) f_{c} b_{w} d \operatorname{sen}^{2} \theta(\cot \alpha+\cot \theta)$ 


\subsection{Eurocode 2 (2004)}

Eurocode 2 [24] indicates the use of Equation 9 to estimate the contribution portion of concrete to the shear strength of beams $\left(V_{R, c}\right)$.

$V_{R, c}=\max \left\{\begin{array}{c}\left(0.18 k\left(100 \rho_{l} f_{c}\right)^{1 / 3}\right) b_{w} d \\ 0.035 k^{\frac{3}{2}} \sqrt{f_{c}} b_{w} d\end{array}\right.$

Where:

$k$ considers the reduction in shear strength due to the size effect, calculated with Equation 10.

$k=1+\sqrt{\frac{200}{d}} \leq 2$

$\rho_{l}$ is the portion related to the longitudinal reinforcement ratio, calculated with $\rho_{l}=\frac{A_{s}}{b_{w} d} \leq 2$, where $A_{s}$ is the area of longitudinal reinforcement of the beam.

Eurocode 2 [24] suggests Equation 11 to check the shear strength of transversely reinforced beams $\left(V_{\mathrm{R}, \mathrm{cs}}\right)$. The code also recommends that the strut's angle of inclination may vary from $21.8^{\circ}$ to $45^{\circ}$. The maximum shear strength $\left(V_{R, \max }\right)$ shall be estimated with Equation 12.

$V_{R, c s}=\max \left\{\begin{array}{c}\frac{A_{s w}}{s} 0.9 d f_{y w}(\cot \theta+\cot \alpha) \operatorname{sen} \alpha \\ V_{R, c}\end{array}\right.$

Where:

$V_{R, \max }=\frac{0.9 b_{w} d v_{1} f_{c}(\cot \theta+\cot \alpha)}{1+\cot ^{2} \theta}$

Where $v 1$ is determined with Equation 13;

$v_{1}=0.6\left[1-\frac{f_{c}}{250}\right]$

As EC2 [24] admits the strut's angle variation, it suggests that Equations 11 and 12 shall be equalized to check the strength so that the smallest strut angle can be found through the derived equation (see Equation 14).

$$
\cot \theta=\sqrt{\frac{b_{w} \mathrm{sv}_{1} f_{\mathcal{C}}}{A_{\mathrm{sw}} f_{\mathrm{yw}} \operatorname{sen} \alpha}}
$$

\subsection{ACI 318 (2014)}

The American code considers the one-way shear strength of reinforced concrete elements to be similar to the strength of a beam, so Equation 15 is used to estimate the shear strength of beams without transverse reinforcement $\left(V_{R, c}\right)$. Among the variables that influence shear strength, the code adopts only the strength of concrete. 
$V_{R, c}=0.17 \sqrt{f_{c}} b_{w} d$

Where:

$f_{c}$ is the compressive strength of concrete, obtained by testing cylindrical specimen;

$b_{w}$ is the width of the beam;

$d$ is the effective depth of the beam.

For the case of beams with transverse reinforcement, ACI 318 [25] considers that the shear strength $\left(V_{R, c s}\right)$ is given by the sum of the contributions of concrete and the transverse reinforcement $\left(V_{R, s}\right)$, calculated with Equation 16 , recalling that the code estimates that the inclination of the compressed strut is equal to $45^{\circ}$. The contribution portion of the shear reinforcement is calculated with Equation 17. In addition, the American code limits the maximum shear strength of beams given by Equation 18, which refers to failure due to crushing of the strut $\left(V_{R, \max }\right)$.

$V_{R, c s}=V_{R, c}+V_{R, s}$

$V_{R, s}=\left(\frac{d}{s}\right) A_{s w} f_{y w}(\operatorname{sen} \alpha+\cos \alpha)$

$V_{R, \max }=0.66 \sqrt{f_{c}} b_{w} d$

Where:

$s$ is the spacing between the transverse reinforcement layers;

$A_{s w}$ is the area of reinforcement of one layer of transverse reinforcement;

$f_{y w}$ is the yield strength of the transverse reinforcement, limited to $420 \mathrm{MPa}$;

$\alpha$ is the angle of inclination of the transverse reinforcement in relation to the longitudinal one.

\section{EXPERIMENTAL PROGRAM}

The experimental program was developed at the Federal University of Pará and consisted of seven tests in reinforced concrete wide beams. The main variables were: the position of supplementary reinforcement; spacing, and inclination of the transverse reinforcement, as shown in Table 1 and Figure 2. This paper presents only the results of beams with prefabricated truss stirrups. Tests with other types of shear reinforcement, such as closed stirrups and studs, are presented in other research [13][22].

Table 1. Characteristics of the tested beams.

\begin{tabular}{|c|c|c|c|c|c|c|c|}
\hline Beam & $\varphi_{\mathrm{w}}(\mathbf{m m})$ & $\mathbf{A}_{\text {sw }}(\mathbf{m m})$ & $\alpha\left({ }^{\circ}\right)$ & $\mathbf{s}(\mathbf{m m})$ & $\rho_{w}(\%)$ & $f_{y w}(\mathrm{MPa})$ & U-Hooks \\
\hline VR & - & - & - & - & - & - & - \\
\hline V1 & \multirow{4}{*}{6.3} & \multirow{2}{*}{196.39} & \multirow{2}{*}{90} & & \multirow{2}{*}{0.39} & \multirow{4}{*}{571} & $\mathrm{~T}+\mathrm{C}$ \\
\hline V2 & & & & 100 & & & $\mathrm{~T}$ \\
\hline V3 & & \multirow{2}{*}{202.62} & \multirow{2}{*}{60} & & \multirow{2}{*}{0.45} & & $\mathrm{~T}+\mathrm{C}$ \\
\hline V4 & & & & & & & $\mathrm{T}$ \\
\hline V5 & \multirow{2}{*}{5.0} & \multirow{2}{*}{123.70} & \multirow{2}{*}{90} & \multirow{2}{*}{60} & \multirow{2}{*}{0.41} & \multirow{2}{*}{676} & $\mathrm{~T}+\mathrm{C}$ \\
\hline V6 & & & & & & & $\mathrm{T}$ \\
\hline
\end{tabular}

Obs.: $b_{w}=500 \mathrm{~mm} ; h=210 \mathrm{~mm} ; L=2300 \mathrm{~mm} ; a=620 \mathrm{~mm} ; d=177 \mathrm{~mm} ; a / d=3.5 ; A_{s}=3434 \mathrm{~mm}^{2} ; f_{y s}=550 \mathrm{MPa} ; \varphi_{\mathrm{f}}=25 \mathrm{~mm} ; \varphi_{\mathrm{f}}=12.5 \mathrm{~mm} ; f_{c m}=29 \mathrm{MPa} ;$ $T=$ supplementary reinforcement on the tensile face; $C=$ supplementary reinforcement on the compression face; $\rho_{w}=\frac{A_{s w}}{b_{w} \text { ssin } \alpha}$ 


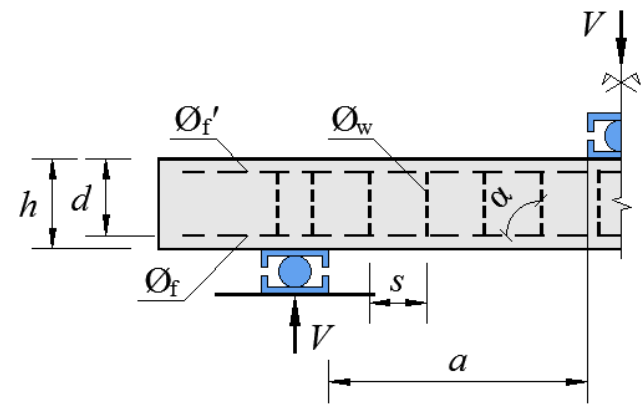

Figure 2. Variables in the experimental program

The test system is shown in Figure 3, consisting of a simply-supported system, where constant and controlled loading was applied by a hydraulic testing machine (capacity of $3000 \mathrm{kN}$ ). All beams were $2300 \mathrm{~mm}$ long, $500 \mathrm{~mm}$ wide, and $210 \mathrm{~mm}$ deep; the a/d ratio was approximately 3.5 to avoid arch action, according to an analysis made by Fisker and Hagsten [26], to allow better visualization of the performance of the transverse reinforcement. The reference beam did not have transverse reinforcement, making it possible to evaluate the increase in the other beams' shear strength due to the transverse and supplementary reinforcement arrangements. The longitudinal reinforcement was kept constant for all tested beams, consisting of 7 bars of $25 \mathrm{~mm}$ in diameter in the tensile area and 7 bars of $12.5 \mathrm{~mm}$ in diameter in the compression area.

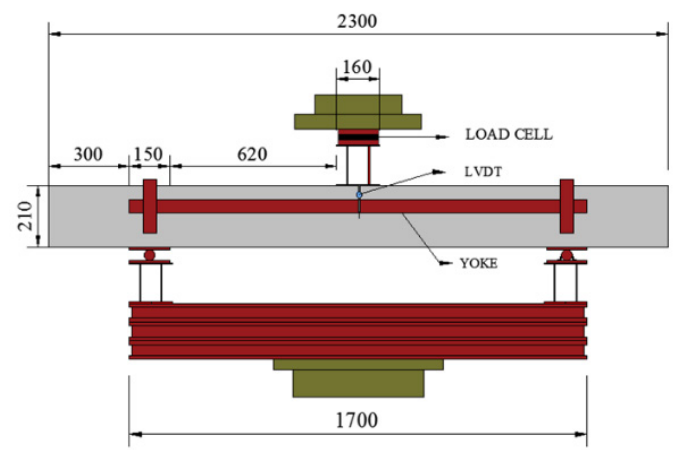

a. Detail of the test system

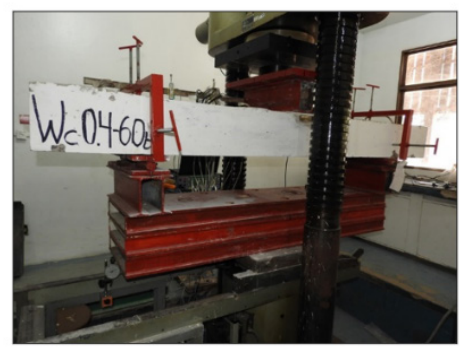

b. Beam during test

Figure 3. Test arrangements.

The shear reinforcement used in this study was composed of prefabricated truss stirrups, developed by Ferreira et al. [22], manufactured in modules and installed between the bottom and top flexural reinforcement shown in Figure 4a. In addition to the transverse reinforcement, $\mathrm{u}$-hook-shaped delamination control reinforcement was used, according to the model adopted by Tapajós [13], as shown in Figure 4b. Figure 4c shows the shear reinforcement's detail. Figure 4d shows the stirrups module manufactured for this research, and Figure $4 \mathrm{e}$ shows the supplementary reinforcement positioned in one of the tested specimens. 


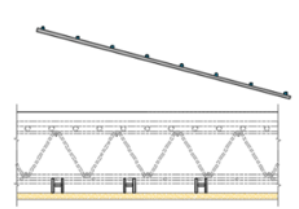

(1)

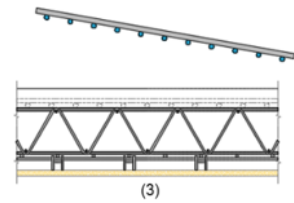

(3)
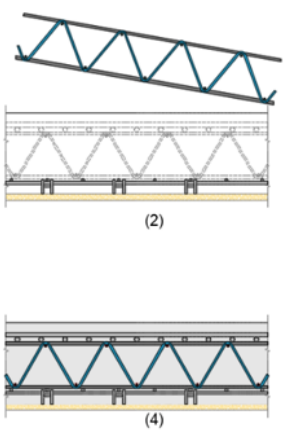

a. The installation process of the reinforcement bars

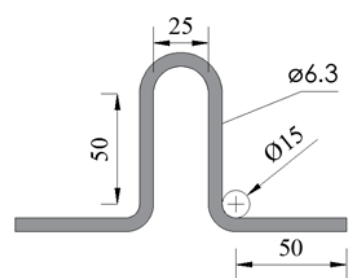

b. Detail of supplementary reinforcement (units in $\mathbf{m m}$ )

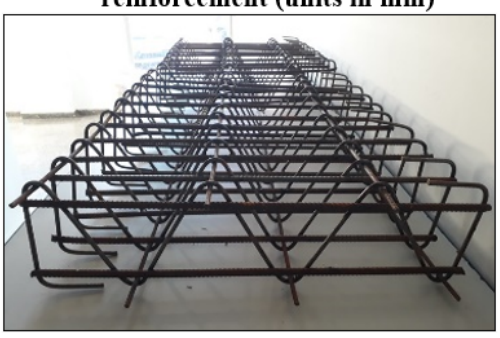

d. Shear reinforcement module

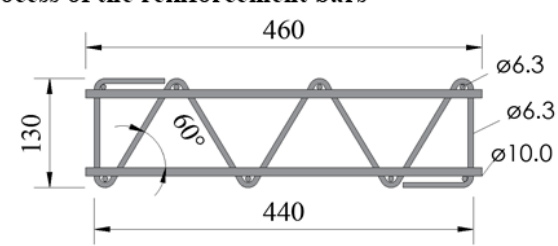

c. Detail of prefabricated stirrups (units in $\mathbf{m m}$ )

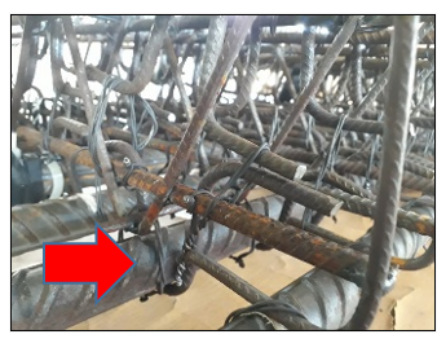

e. Supplementary reinforcement

Figure 4. Prefabricated truss stirrups.

Shear reinforcement with inclinations of $60^{\circ}$ and $90^{\circ}$ were used to evaluate the influence of their inclination in the shear resistance of the tested beams. To analyse the influence of layer's spacing on the shear strength, two arrangements were adopted: stirrups with $6.3 \mathrm{~mm}$ in diameter spaced every $100 \mathrm{~mm}\left(\rho_{\mathrm{w}}=0.39 \%\right.$ for V1 and $\mathrm{V} 2$ and $\rho_{\mathrm{w}}=0.45 \%$ for V3 and V4) and stirrups with $5 \mathrm{~mm}$ in diameter spaced every $60 \mathrm{~mm}\left(\rho_{\mathrm{w}}=0.41 \%\right)$, both arrangements having approximately the same transverse reinforcement ratio. Finally, to observe each specimen's behaviour depending on the supplementary reinforcement position, beams with the u-hooks on their tensile and compression parts were tested, as well as specimens that only had u-hooks on the tensile zone of the beam. All beams with prefabricated truss stirrups had two vertical legs and five inclined legs at $60^{\circ}$. In this paper, any inclined leg relates to a 0.87 vertical leg $\left(\sin 60^{\circ}\right.$ ), so there are approximately 6.35 legs by layer of the prefabricated truss stirrup. Figure 5 shows a summary of the tested beams.

Regarding the variables involved, beam VR is a reference specimen without shear reinforcement. Beams V1 and V2 had vertical $\left(90^{\circ}\right)$ prefabricated truss stirrups made with $6.3 \mathrm{~mm}$ bars spaced at each $100 \mathrm{~mm}$, and beam V1 had supplementary reinforcement arranged in the tensile and compression faces of the specimen, while beam V2 only had supplementary reinforcement on the tensile face. Beams V3 and V4 had the same shear reinforcement of beams V1 and V2, but with stirrups inclined at $60^{\circ}$. Beam V3 had supplementary u-hooks on both faces, while in beam V4, they were placed only on the tensile face. Finally, beams V5 and V6 were tested to evaluate the influence of spacing between layers, their shear reinforcement being manufactured with stirrups of $5 \mathrm{~mm}$ in diameter, spaced every $60 \mathrm{~mm}$ and with an angle of inclination of $90^{\circ}$, beam V5 having supplementary reinforcement on both faces, whereas beam V6 only had it on the tensile face. In this way, all beams with shear reinforcement had approximately the same transverse reinforcement ratio. 


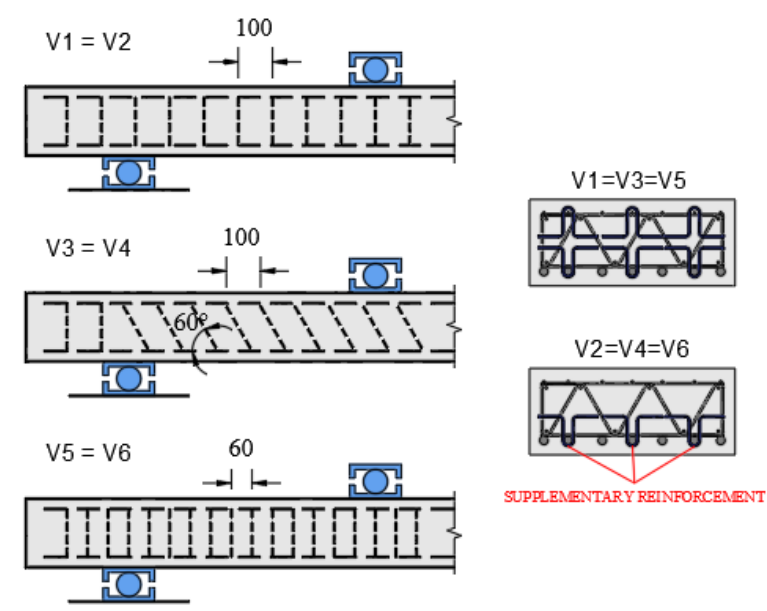

Figure 5. Characteristics of the tested beams (units in $\mathrm{mm}$ )

Concrete was produced with $C P I V-Z$ cement (Portland cement with pozzolanic addition). The coarse aggregate adopted had a maximum size of $19 \mathrm{~mm}$ and granitic origin, and medium sand was used as fine aggregate. Concrete was mixed to reach grade C30. All the beams were cast on the same day, and after 60 days, the tests were carried during a week. The compressive strength of concrete was obtained through axial compression tests, as recommended by NBR 5739 [27]. On the day of each beam's test, three concrete cylindrical specimens were tested to obtain the mean and characteristic value of concrete's compressive strength. The mean value of concrete compressive strength in all tests is considered as $f_{c m}=29 \mathrm{MPa}$, while the characteristic value of compressive strength of concrete is the mean value less than $4 \mathrm{MPa}$, due to rigorous control in the laboratory $\left(f_{c k}=25 \mathrm{MPa}\right)$. Thus, to calculate the beams' strength according to the design codes, the mean values were used. For reinforcement, CA-60 steel was used for the bars with $5 \mathrm{~mm}$ in diameter and CA-50 steel for the other diameters. The steel's mechanical properties were obtained through tensile tests, following the recommendations of NBR 6892 [28]. Table 1 presents materials properties used to estimate shear strength by theoretical recommendations.

Strain gauges (SG) were attached to the beams' upper side face, in the midspan between the supports in the beams' longitudinal direction, to measure the compression strains of concrete. Regarding the flexural reinforcement instrumentation, two SG were attached to each beam's central bar in the midspan to obtain the maximum tensile strains, adopting the average of the two measured values.

Concerning the shear reinforcement, two SG were attached to each instrumented bar, choosing to instrument the layers arranged in the middle of the shear span, where it is estimated that the greatest strains in transverse reinforcement occur, as observed by Ferreira et al. [22] and Tapajós [13]. SG were also used in the supplementary reinforcement to observe its behaviour during the test. Figure 6 shows the complete instrumentation arrangement of the tested beams.
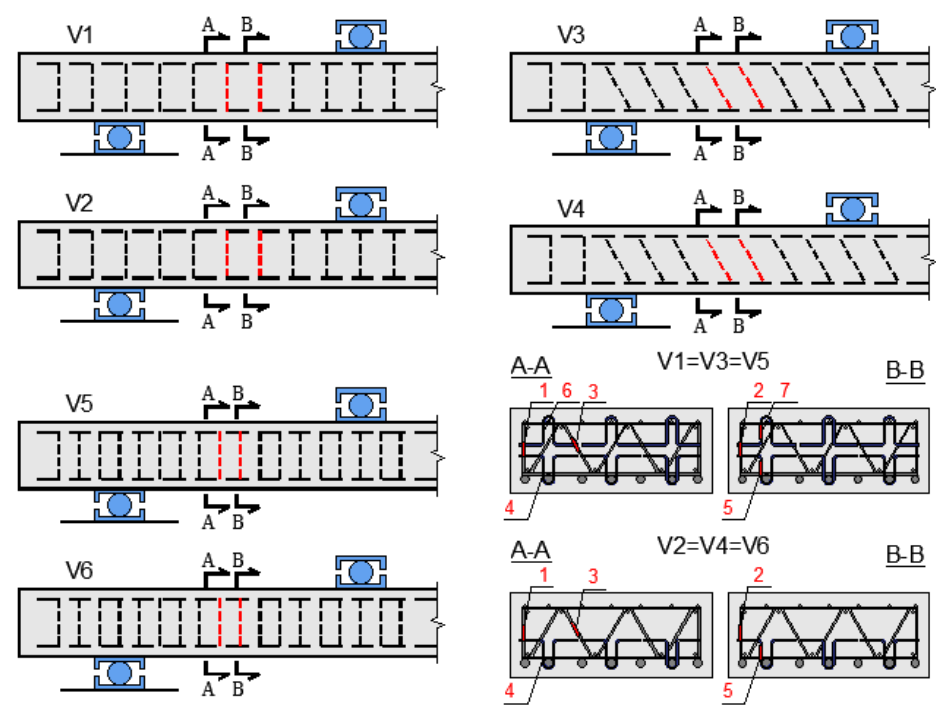

Figure 6. Instrumentation arrangement of the beams. 


\section{RESULTS AND DISCUSSIONS}

\subsection{Ultimate strength and theoretical estimates}

Table 2 shows the experimental results of the tested beams, related to their ultimate strengths, as well as the comparison with their flexural strength estimates $\left(V_{f l e x}\right)$, the performance in relation to the reference beam, to observe the increase in strength due to the transverse reinforcement, and the comparison with the theoretical shear strength estimates, obtained following the recommendations of models I and II of NBR 6118 [23], Eurocode 2 [24] and ACI 318 [25], as presented in section 2 .

It was observed that all tested beams had an ultimate strength lower than the estimated flexural strength, contributing to the understanding that the specimens' failure was related to shear. Concerning the comparison with the reference beam, all specimens showed a significant increase in strength, varying between $89 \%$ and $158 \%$, showing that the prefabricated truss stirrups contribute to the increase in shear strength, as observed by Ferreira et al. [22].

Table 2. Failure Loads of the tested beams.

\begin{tabular}{|c|c|c|c|c|c|c|c|}
\hline \multirow{2}{*}{ Beam } & \multirow{2}{*}{$V_{u}(\mathrm{kN})$} & \multirow{2}{*}{$V_{u} / V_{\text {flex }}$} & \multirow{2}{*}{$V_{u} / V_{r e f}$} & \multicolumn{2}{|c|}{$V_{u} V_{R . N B R}(k N)$} & \multirow{2}{*}{$\mathbf{V}_{\mathbf{u}} / \mathbf{E C 2}$} & \multirow{2}{*}{$V_{u} / A C I$} \\
\hline & & & & I & II & & \\
\hline VR & 145.0 & 0.37 & 1.00 & 1.38 & 1.38 & 1.18 & 1.79 \\
\hline V1 & 281.5 & 0.72 & 2.07 & 1.08 & 0.87 & 0.67 & 1.24 \\
\hline $\mathrm{V} 2$ & 256.5 & 0.66 & 1.89 & 0.98 & 0.80 & 0.61 & 1.13 \\
\hline V3 & 351.0 & 0.90 & 2.58 & 1.10 & 0.94 & 0.74 & 1.25 \\
\hline V4 & 269.0 & 0.69 & 1.98 & 0.84 & 0.72 & 0.57 & 0.96 \\
\hline V5 & 345.5 & 0.89 & 2.57 & 1.30 & 1.05 & 0.83 & 1.50 \\
\hline V6 & 302.0 & 0.77 & 2.23 & 1.13 & 0.92 & 0.72 & 1.30 \\
\hline \multicolumn{4}{|c|}{ Average } & 1.12 & 0.95 & 0.76 & 1.31 \\
\hline \multicolumn{4}{|c|}{ Coefficient of Variation (\%) } & 16.3 & 22.4 & 26.9 & 20.4 \\
\hline
\end{tabular}

The beams with supplementary reinforcement at both end showed greater strength than the specimens with the u-hooks only on the tensile face. Tapajós [13] research points to a better performance of beams with supplementary reinforcement when compared with those without it. However, the comparison between the arrangement on the two faces or only on the tensile face was not addressed.

Concerning the transverse reinforcement's inclination, specimens with truss stirrups inclined at $60^{\circ}$ had greater strength than those with the same arrangement and inclination of $90^{\circ}$. As pointed out by several studies, this result was expected, including Melo et al. [29] on inclined stirrups' better performance compared to vertical stirrups.

Regarding stirrup spacing, it was observed that beams with a spacing of $60 \mathrm{~mm}$ between layers of transverse reinforcement, V5, and V6, reached higher strengths than the specimens with a spacing of $100 \mathrm{~mm}$ between layers, V1, and V2. It is worth mentioning that both specimens had approximately the same transverse reinforcement ratio. V3 and V4 were cast with inclined shear reinforcement. These beams reach a strength greater than V1 and V2, in order of comparison, due to a better anchorage because the inclined shear reinforcement while had a similar strength than the beams with lower spacing between layers.

When comparing the theoretical and experimental results, it was observed that Model II of NBR 6118 [23] presented the average results closest to the experimental ones, however with most results against safety and the second highest coefficient of variation. In contrast, Model II of the same code presented the least dispersion of results among the recommendations evaluated, with the second average of results closer to the experimental ones and few results against safety. Eurocode 2 [24] presented the least safe average of results and the higher dispersion. However, it is worth mentioning that all recommendations showed results against safety, including ACI 318 [25], which presents more conservative recommendations. This behaviour may be related to the high transverse reinforcement ratio adopted in this research since, as the transverse reinforcement ratio increases, there is a trend towards more unsafe results, as verified by Tapajós [13]. It is also observed that Model I of the Brazilian code and the American code set the value of the strut's angle of inclination at $45^{\circ}$, while Model II of the Brazilian code and the recommendations of the European code allow the reduction of this angle, leading to higher strength estimates when compared with the other two models. It is worth mentioning that these results were obtained without considering the safety coefficients of the codes. Figure 7 shows the comparison of experimental and theoretical results. 


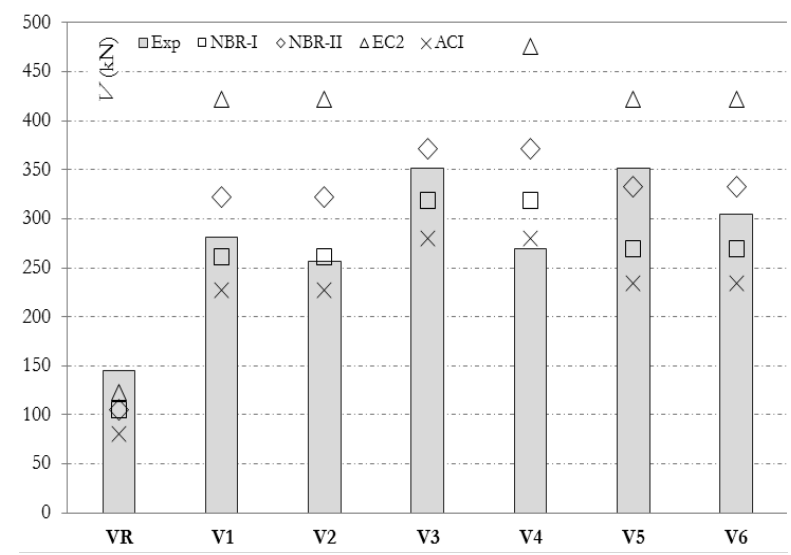

Figure 7. Comparison of experimental and theoretical results.

\subsection{Vertical displacement and strain of the flexural reinforcement}

Figure 8 shows the graph that correlates the shear force and displacement for the seven tested beams. All beams showed similar behaviour to the reference beam for the same loading level and concerning beams V1, V2, V3, V4, V5, and V6, close displacements among them were observed for the same loading level. However, after reaching approximately $200 \mathrm{kN}$, more significant displacements were noticed in beam V4. Only beam V5 showed a further increase in strength after reaching the peak.

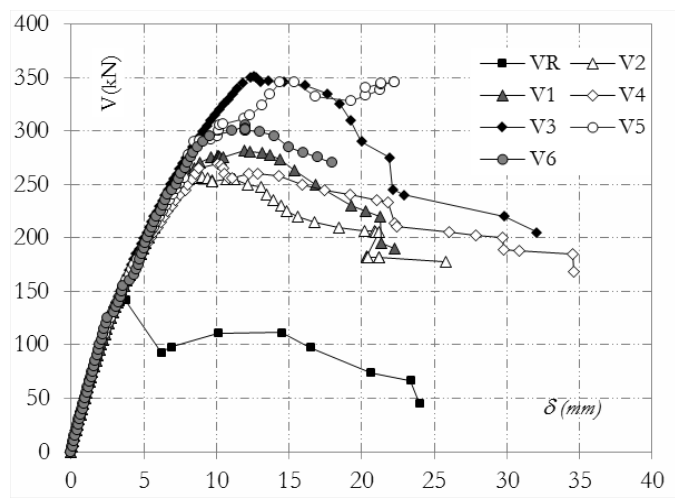

Figure 8. Vertical displacement of the beams.

Figure 9 shows the graph of shear force $\mathrm{x}$ strain of the flexural reinforcement. For all beams, the flexural bars did not reach the yield strain, ruling out the possibility of flexural failure, as observed in Table 2, comparing the ultimate strength with the flexural strength estimate.

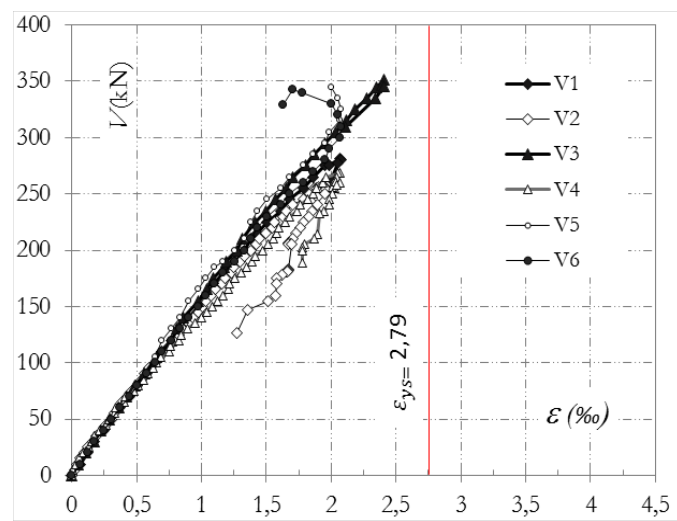

Figure 9. Strains on the flexural reinforcement. 


\subsection{Strain of the transverse reinforcement}

Figure 10 shows the graphs of the relation between the strain of stirrups and the shear force. Two yield strain lines are presented since the beams V1, V2, V3, and V4 were produced with bars of $6.3 \mathrm{~mm}$ in diameter and beams V5 and V6 with bars of $5 \mathrm{~mm}$ in diameter. The result seen in Figure 9 follows the instrumentation arrangement shown in Figure 5, with Figure 9a showing the strain readings of bar 1 from the tested beams, Figure $9 \mathrm{~b}$ the strain of bar 2, and Figure 10c the strain of bar 3 .

Figure 10a shows that only beam V5 presented yield of the shear reinforcement at position 1, suggesting that it is the least required position during the test. It is also believed that this beam presented yield of the transverse reinforcement due to the lower area of reinforcement per layer. The same did not happen with the other beam with smaller spacing, V6, probably because it only had supplementary reinforcement on the tensile face.

In Figure 10b, it is possible to observe higher strains at position 2 of the instrumentation, estimating that this stirrup layer was the most stressed during the tests. Besides, stirrups yielded in all beams where supplementary reinforcement was placed in both edges of the shear reinforcement, confirming that they are relevant to improve anchorage conditions and the tested beams' structural performance.

Position 3 of the instrumentation refers to the same layer at position 1, but on one of the bar's inclined legs, located closer to the center of the beam's cross-section. In Figure 10c, it is possible to observe that the strains were higher than those at position 1, which shows greater stress concentrations in the central region of the beam and inclined legs, as also observed by Tapajós [13]. It was also possible to notice that all the reinforcement at position 3 yielded, pointing out a good performance of the prefabricated truss stirrups and confirming the failure mode associated with shear.

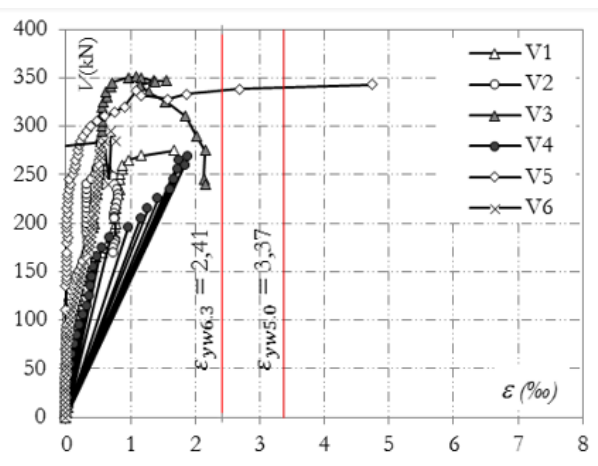

a. Bar 1

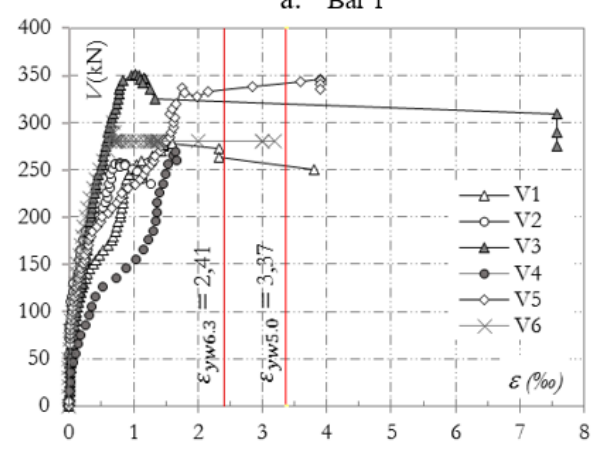

b. Bar 2

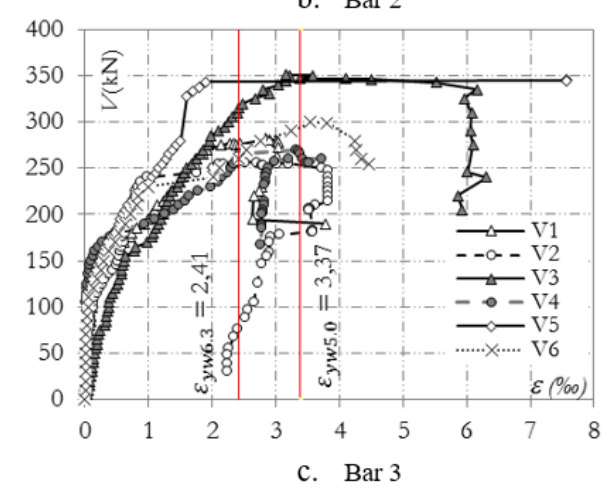

Figure 10. Strain of the shear reinforcement. 


\subsection{Strain of the supplementary reinforcement}

Figure 11 shows the result of strains of the supplementary reinforcement of the tested beams. Tapajos [13] had observed higher strengths and strains on the truss stirrups in the beams with supplementary reinforcement than in the beams without supplementary reinforcement, but he did not complete the instrumentation of these u-hooks to prove their efficiency. However, in this research, it was possible to prove that this supplementary reinforcement works during the test.

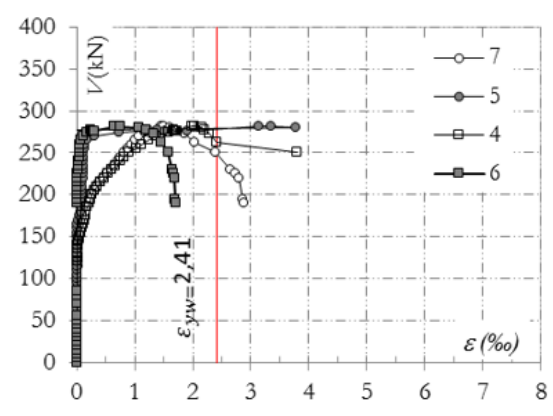

a) V1

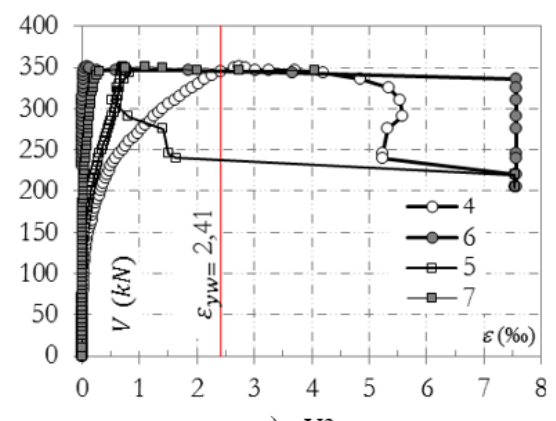

c) V3

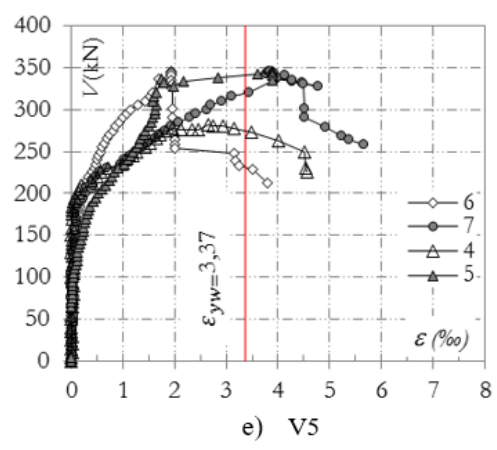

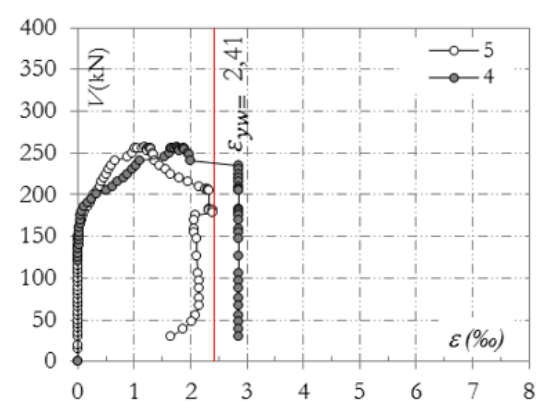

b) V2

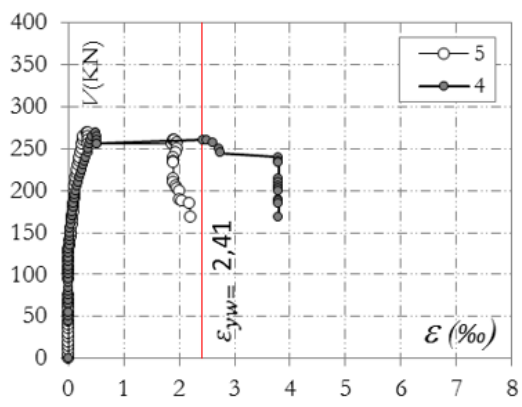

d) V4

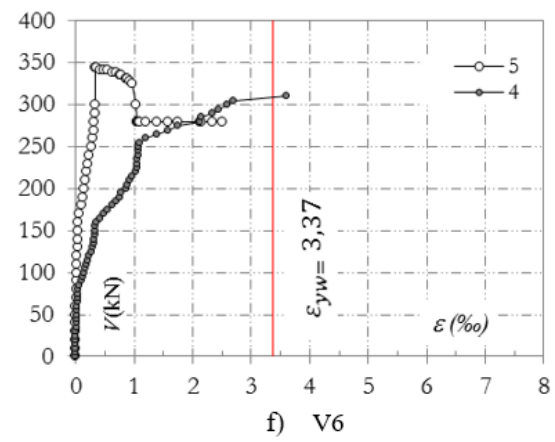

Figure 11. Strains on the supplementary reinforcement.

In general, the beams $\mathrm{V} 1, \mathrm{~V} 3$, and $\mathrm{V} 5$, which were produced with supplementary reinforcement on the tensile and compression faces, presented higher strains than the beams V2, V4, and V6, which only had u-hooks on the tensile face. Thus, u-hooks on both edges of the shear reinforcement improved the tested beams' performance, as their transverse reinforcement reached higher strengths, with positive reflections on their ultimate strengths.

In most of the tested beams, the supplementary reinforcement only reached the yield strain after the beam reached its maximum strength, which indicates that this supplementary reinforcement acts sewing the cracks by delamination, avoiding a brittle failure of the specimens. Besides, the behaviour of beam V5 stands out, where all the instrumented u-hooks reached the yield strain, some of them even before the specimen reached its maximum strength. Thus, it is estimated that the conditions presented by this specimen were the most favourable in this study to ensure better anchorage of the prefabricated truss stirrups, together with the supplementary reinforcement on both faces. 


\subsection{Cracking patterns}

Figure 12 shows the tested beams' cracking patterns, where it is possible to observe that all beams have failed due to shear, with the inclination of the main crack varying between $22^{\circ}$ and $31^{\circ}$. Cracks by delamination were observed in all tested specimens. However, these cracks were controlled, unlike the beams tested by some authors [13][22] that did not have supplementary reinforcement, validating the hypothesis that these u-hooks contribute to preventing this propagation, as seen in the strain gauges' readings. It was also found that the beams with the smallest spacing between the layers of shear reinforcement showed a greater inclination for their main failure cracks.

It was observed that beams with supplementary reinforcement in both faces presented less delamination crack on the top face of the specimen when compared to the beams with u-hooks on the bottom face. The beams with shear reinforcement inclined at $60^{\circ}$ could control satisfactory the cracks by delamination due to the increase of length anchorage compared to the vertical stirrups. Concerning spacing, the lower spacing between the layers contributes to control the crack propagation.

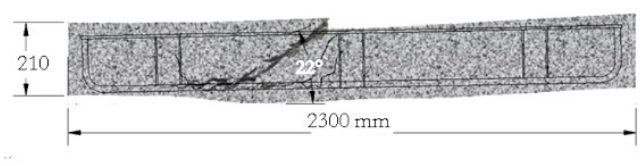

a) VR

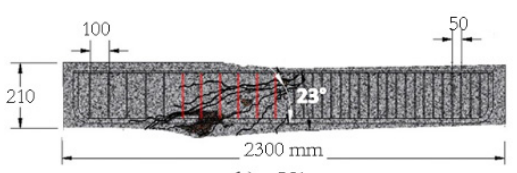

b) V1

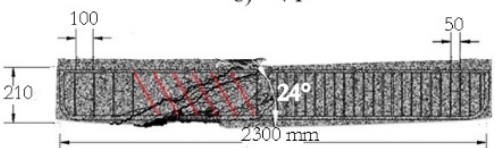

d) V3

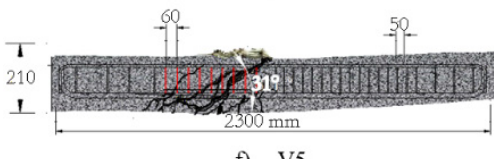

f) V5

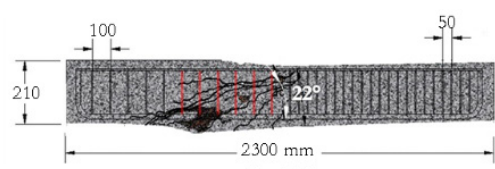

c) V2

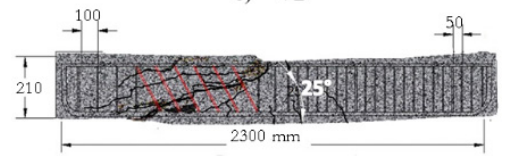

e) V4

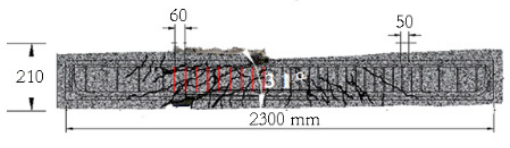

g) V6

Figure 12. Cracking patterns of the specimens.

\section{CONCLUSIONS}

This study analysed the behaviour of reinforced concrete wide beams subjected to shear with prefabricated truss stirrups proposed by Ferreira et al. [22] and supplementary reinforcement tested by Tapajós [13]. In addition to the experimental investigation, the ultimate strengths of the tested specimens were also compared with the strength estimates following the recommendations of NBR 6118 [23], Eurocode 2 [24], and ACI 318 [25].

Concerning the use of the supplementary reinforcement, it was found that the shear reinforcement has a better performance when this supplementary reinforcement is used on both faces of the beam, instead of just adopting it on the tensile face. Regarding the inclination of the transverse reinforcement, specimens that had an inclination of $60^{\circ}$ showed greater strength when compared with similar specimens with an inclination of $90^{\circ}$. Regarding the spacing between shear reinforcement layers, the strengths were higher for beams with less spacing and a lower area of reinforcement per layer than for the specimens with a greater area of reinforcement per layer and greater spacing, even though they had approximately the same transverse reinforcement ratio.

When comparing theoretical and experimental results, results against safety were observed for all recommendations, with a greater amount for Model II of NBR 6118 [23] and Eurocode 2 [24]. This behaviour was in line with what was observed by Tapajós [13], who points out a trend towards more unsafe results with a higher transverse reinforcement ratio when adopting the prefabricated truss stirrups as shear reinforcement.

Concerning the design of beams with prefabricated truss stirrups, with transverse reinforcement ratio approximately equal to $0.40 \%$, Model I of NBR 6118 [23] and ACI 318 [25] are more recommended, if the supplementary 
reinforcement is used on the tensile and compression faces of the beam, with no results against safety in these arrangements. It is worth mentioning that these recommendations are specific and were obtained based on this study, so for broader conclusions and conditions, it is necessary to carry out further experimental research to observe the performance.

\section{ACKNOWLEDGMENTS}

The authors would like to thank CAPES, CNPq, NUMEA, LEC CAMTUC/UFPA, and NDAE/UFPA for their support in the development of this research.

\section{REFERENCES}

[1] Y. Yoon, W. D. Cook, and D. Mitchell, "Minimum shear reinforcement in normal, medium, and high-strength concrete beams," ACI Struct. J., vol. 93, no. 5, pp. 576-584, 1996.

[2] G. Russo and M. Pauletta, "Seismic behavior of exterior beam-column connections with plain bars and effects of upgrade," $A C I$ Struct. J., vol. 109, no. 2, pp. 225-233, 2012.

[3] B. Bresler and A. C. Scordelis, "Shear strength of reinforced concrete beams," ACI Struct. J., vol. 60, no. 1, pp. 51-74, 1963.

[4] K. N. Rahal and K. S. Al-Shaleh, "Minimum transverse reinforcement in 65 MPa concrete beams," ACI Struct. J., vol. 101, no. 6, pp. 872-878, 2004.

[5] C. Cucchiara, M. Fosseti, and M. Papia, "Minimum transverse reinforcement in 65 MPa concrete beams," Struct. Eng. Mech., vol. 42, pp. 551-570, 2012.

[6] N. Spinella, P. Colajanni, and A. Recupero, "A simple plastic model for shear critical sfrc beams," J. Struct. Eng., vol. 136, no. 4, pp. 390-400, 2010.

[7] P. Colajanni, A. Recupero, and N. Spinella, "Generalization of shear truss model to the case of SFRC beams with stirrups," Comput. Concr., vol. 9, no. 3, pp. 227-244, 2012.

[8] N. Spinella, P. Colajanni, and L. La Mendola, "Nonlinear analysis of beams reinforced in shear with stirrups and steel," ACI Struct. J., vol. 109, no. 1, pp. 53-64, 2012.

[9] G. Russo, D. Mitri, and M. Pauletta, "Shear strength design formula for RC beams with stirrups," Eng. Struct., vol. 51, pp. 226-235, 2013.

[10] W. De Corte and V. Boel, "Effectiveness of spirally shaped stirrups in reinforced concrete beams," Eng. Struct., vol. 52, pp. 667-675, 2013.

[11] C. G. Karayannis and C. E. Chalioris, "Shear tests of reinforced concrete beams with continuous rectangular spiral reinforcement," Constr. Build. Mater., vol. 46, pp. 86-97, 2013.

[12] A. S. Lubell, E. C. Bentz, and M. P. Collins, "Shear Reinforcement Spacing in Wide Members," ACI Struct. J., vol. 106, no. 2, pp. 205-214, 2009.

[13] L. S. Tapajós, "Cisalhamento em elementos de concreto armado com estribos desconectados," Dissertação de Mestrado, Instituto de Tecnologia, Universidade Federal do Pará, Belém, 2017, 98p.

[14] P. E. Regan, "Shear Reinforcement of Flat Slabs. International Workshop on Punching Shear Capacity of RC Slabs - Proceedings," TRITA-BKN Bulletin, vol. 57, pp. 99-107, 2000.

[15] R. Beutel and J. Hegger, "The Effect of Anchorage on the Effectiveness of the Shear Reinforcement in the Punching Zone," Cement Concr. Compos., vol. 24, pp. 539-549, 2002.

[16] T. Yamada, A. Nanni, and K. Endo, "Punching Shear Resistance of Flat Slabs: Influence of Reinforcement Type and Ratio," ACI Struct. J., vol. 88, no. 4, pp. 555-563, 1992.

[17] R. B. Gomes and M. A. S. Andrade, "Does a punching shear reinforcement need to embrace a flexural reinforcement of a RC flat slab?," in Proc. Int. Workshop on Punching Shear Capacity of RC Slabs, Jun. 2000, pp. 109-117.

[18] P. E. Regan and F. Samadian, "Shear Reinforcement against Punching in Reinforced Concrete Flat Slabs," Struct. Eng., vol. 79, no. 10, pp. 24-31, 2001.

[19] H. Park, K. Ahn, K. Choi, and L. Chung, "Lattice Shear Reinforcement for Slab-Column Connections," ACI Struct. J., vol. 104, no. 3, pp. 294-303, 2007.

[20] L. M. Trautwein, T. N. Bittencourt, R. B. Gomes and J. C. D. Bella, "Punching Strength of Flat Slabs with Unbraced Shear Reinforcement," ACI Struct. J., vol. 108, no. 2, pp. 197-205, 2011.

[21] A. P. Caldentey, P. P. Lavaselli, H. C. Peiretti, and F. A. Fernández, "Influence of Stirrup Detailing on Punching Shear Strength of Flat Slabs," Eng. Struct., vol. 49, pp. 855-865, 2013. 
[22] M. P. Ferreira, R. N. M. Barros, M. J. M. Pereira Filho, L. S. Tapajós and F. S. Quaresma, "One-Way Shear Resistance of RC Members with Unconnected Stirrups," Lat. Am. J. Solids Struct., vol. 13, pp. 2670-2690, 2016.

[23] Associacao Brasileira de Normas Tecnicas, Projeto de Estruturas de Concreto - Procedimento, NBR 6118, 2014.

[24] European Committee for Standardization, Eurocode 2: Design of Concrete Structures-Part 1-1: General Rules and Rules for Buildings, EN 1992-1-1, 2004.

[25] American Concrete Institute, Building Code Requirements for Structural Concrete, ACI 318, 2014.

[26] J. Fisker and L. G. Hagsten, "Mechanical Model for the Shear Capacity of R/C Beams without Stirrups: A proposal Based on Limit Analysis," Eng. Struct., vol. 115, pp. 220-231, 2016.

[27] Associacao Brasileira de Normas Tecnicas. Concreto - Ensaio de compressão de corpos-de-prova cilíndricos, NBR $5739,2007$.

[28] Associacao Brasileira de Normas Tecnicas. Materiais metálicos - Ensaio de tração à temperatura ambiente, NBR 6892, 2013.

[29] G. S. S. Melo, A. E. G. Coelho, and D. R. C. Oliveira, "RC flat slabs with inclined stirrups as shear reinforcement," in Proc. Int. Workshop on Punching Shear Capacity of RC Slabs, Jun. 2000, pp. 155-162.

Author contributions: RSP and LST: conceptualization, formal analysis, writing-original draft; writing-review \& editing; VCS: data curation, investigation; MPF and AFLN: conceptualization, funding acquisition, project administration, resources, supervision, writing-original draft, writing-review \& editing.

Editors: Samir Maghous, Guilherme Aris Parsekian. 